\title{
Ayahuasca: what mental health professionals need to know
}

\author{
Rafael Guimarães dos Santosi,2,3, José Carlos Bouso ${ }^{3}$, Jaime Eduardo Cecilio Hallaki1,2
}

1 Department of Neurosciences and Behavior, Ribeirão Preto Medical School, University of São Paulo (FMRP-USP), Ribeirão Preto, SP, Brazil.

2 National Institute for Translational Medicine (INCT-TM), CNPq, Ribeirão Preto, SP, Brazil.

3 International Center for Ethnobotanical Education, Research and Service, ICEERS, Barcelona, Spain.

Received: 04/04/2017 - Accepted: 05/04/2017

DOl: 10.1590/0101-60830000000130

\begin{abstract}
Background: Ayahuasca is a psychoactive ethnobotanical concoction that has been used for decades by indigenous groups of the Northwestern Amazon and by syncretic religious organizations for ritual and therapeutic purposes. In the last two decades, it is being used worldwide in evolving practices. Ayahuasca seem to therapeutic effects, but controlled studies are lacking. Moreover, its safety and toxicity are not completely understood. Objectives: To present an overview of the effects of ayahuasca based on the most recent human studies. Methods: Narrative review. Results: Ayahuasca administration in controlled settings appears to be safe from a subjective and physiological perspective, with few adverse reactions being reported. More frequent adverse reactions occur in non-controlled settings. Prolonged psychotic reactions are rare and seem to occur especially in susceptible individuals. Ayahuasca showed antidepressive, anxiolytic, and antiaddictive effects in animal models, observational studies, and in open-label and controlled studies. Discussion: Ayahuasca administration in controlled settings appear to be safe. Moreover, ayahuasca seem to have therapeutic effects for treatment-resistant psychiatric disorders that should be further investigated in randomized controlled clinical trials. However, medical complications and cases of prolonged psychotic reactions have been reported, and people with personal or family history of psychotic disorders should avoid ayahuasca intake.
\end{abstract}

Santos RG et al. / Arch Clin Psychiatry. 2017;44(4):103-9

Keywords: hallucinogens, ayahuasca, dimethyltryptamine, psychopharmacology, mental health.

\section{Introduction}

Ayahuasca (from the Quechua Aya - "soul”, "dead spirit"; and Waska"rope" "vine") is a natural psychoactive concoction used for centuries by indigenous groups from Northwestern Amazonian countries such as Brazil, Peru, Colombia and Ecuador for ritual, religious, and therapeutic purposes ${ }^{1}$. Ayahuasca has dozens of indigenous names, such as Yajé, Kamarampi and Huni, and is also used by the nonindigenous mestizo populations of these countries. Syncretic religious organizations that originated in Brazil in the 1930-1960's such as the Santo Daime, Barquinha, and União do Vegetal (UDV) use ayahuasca as a sacrament, where is known as daime, vegetal or hoasca. In the last 25 years, these groups spread from Brazil to Europe, the United States, Asia and Africa ${ }^{2,3}$.

\section{Botany, chemistry and mechanism of action}

The main ingredient of ayahuasca is the vine Banisteriopsis caapi (Figure 1), which contains $\beta$-carbolines alkaloids such as harmine, tetrahydroharmine $(\mathrm{THH})$ and harmaline (Figure 2$)^{4}$. The vine is commonly used in combination with lots of different plants depending on the purpose of the ceremony ${ }^{1,2,4}$. In the Western world, ayahuasca is known to be the mixture of the vine B. caapi with the leaves of Psychotria viridis (Figure 1) or from the vine Diplopterys cabrerana, that contain the tryptamine hallucinogen dimethyltryptamine (DMT) (Figure 2). This probably happened because of the international expansion of ayahuasca by the Brazilian ayahuasca churches and also by South American shamans ${ }^{4}$. The beverage is usually prepared by the prolonged decoction of these plants and has a brownish color (Figure 1).

DMT is not active when ingested alone because it is metabolized in the gastrointestinal tract and in the liver by monoamine oxidase $\mathrm{A}$ (MAO-A). However, the $\beta$-carbolines in the vine reversibly inhibit MAO-A and allow DMT to reach the Central Nervous System ${ }^{4-6}$. The main mechanism of action of DMT appears to partial agonism on serotonergic $2 \mathrm{~A}\left(5-\mathrm{HT}_{2 \mathrm{~A}}\right)$ receptors expressed on layer $\mathrm{V}$ cortical neurons, a process that also seems to involve metabotropic glutamate

receptors $(\mathrm{mGluR})^{7,8}$. DMT is an endogenous compound, although its physiological functions are not known ${ }^{9,10}$. There is some evidence that endogenous DMT could act as a neurotransmitter on sigma receptors $^{11,12}$, but human studies suggest that the psychoactive effects of classic/serotonergic hallucinogens such as lysergic acid diethylamide (LSD), psilocybin and DMT are mainly mediated by the $5-\mathrm{HT}_{2 \mathrm{~A}}$ receptor ${ }^{8,13-15}$.

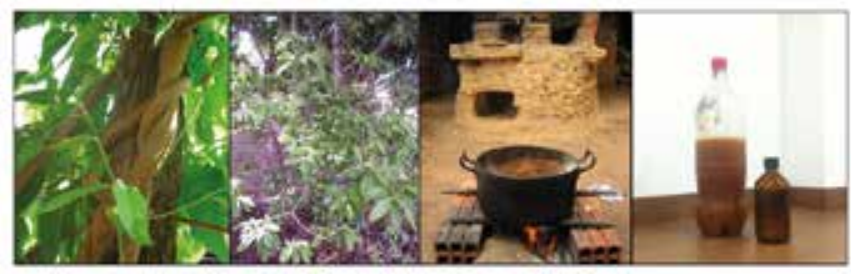

Figure 1. Ayahuasca preparation (from right to left): Banisteriopsis caapi; Psychotria viridis; ayahuasca decoction; ayahuasca prepared and bottled. Photographs by Rafael G. dos Santos.

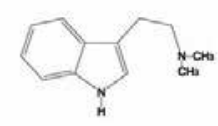

DMT

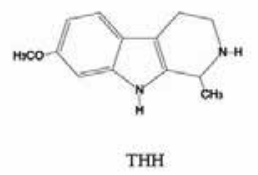

Figure 2. Chemical structures of the ayahuasca alkaloids: dimethyltryptamine (DMT); harmine; tetrahydroharmine (THH); and harmaline. 


\section{Subjective effects}

The subjective effects of ayahuasca (and other hallucinogens) are difficult to describe and measure ${ }^{16,17}$. Experimental studies with healthy volunteers and longitudinal studies with experienced ayahuasca users show that these subjective effects include increases in introspection, serenity, and in experiencing memories with autobiographical content, positive mood, affect, and wellbeing, altered perception of colors and sounds often accompanied by synesthesia, and also mystical-like and religious experiences (Table $1)^{16,18-21}$. In the clinical studies, the variable that measure volition (or the capacity to interact with the environment) is only slightly affected and subjects usually rate the experience as "good effects" and "liking", while the ratings on "drunken" and "bad effects" are the variables with the lower scores ${ }^{5,19}$. Administration of two consecutive doses of ayahuasca four hours apart does not seem to induce tolerance or sensitization to the psychological effects ${ }^{19}$. Dysphoric reaction are less frequent and my include anxiety, fear, and psychotomimetic symptoms, but these effects are generally transient and usually do not need medical intervention $16,18,20,21$. Prolonged dysphoric or psychotic reactions in controlled contexts (experimental or ritual) are rare and seem to occur mostly among individuals with a personal or family psychiatric history, although cases where there was no personal of family antecedent have also been reported (Table 1)22,23.

Table 1. Subjective and physiological effects of ayahuasca

\begin{tabular}{|l|}
\hline Positive subjective effects (acute)16,18-21 \\
\hline Introspection \\
\hline Serenity \\
\hline Memories with autobiographical content \\
\hline Positive mood, affect and wellbeing \\
\hline Altered perception of colors and sounds (synesthesia) \\
\hline Mystical/religious experiences \\
\hline Negative subjective effects (acute/subacute)16,18,20-22 \\
\hline Anxiety, panic, and fear \\
\hline Psychotic symptoms (less common) \\
\hline Negative subjective effects (prolonged)22,59 \\
\hline Psychotic reactions (rare) \\
\hline Physiological effects (acute)5,14,18,19,21,24 \\
\hline Moderate increases in blood pressure and heart rate \\
\hline Mydriasis \\
\hline Increases in body temperature \\
\hline Increases in prolactin, cortisol, and growth hormone secretion \\
\hline Increases in natural killer cells levels \\
\hline Decreases on CD3 and CD4 lymphocyte levels \\
\hline
\end{tabular}

\section{Physiological effects}

Experimental studies with healthy volunteers showed that administration of a single ayahuasca dose induced moderate and transient (less than 24 hours) increases in blood pressure and heart rate, on prolactin, cortisol, and growth hormone (GH) levels, on pupil size and body temperature, and in natural killer (NK) cells levels. Ayahuasca administration also induced transitory decreases on lymphocyte (CD3 and CD4) levels (Table 1)5,14,18,19,21,24. Two consecutive doses of ayahuasca did not induce tolerance or sensitization for most physiological variables, but a trend to lower cardiovascular activation was observed, and tolerance was reported to $\mathrm{GH}$ secretion ${ }^{19}$.

\section{Neurophysiological and neuroimaging studies}

The effects of ayahuasca on brain dynamics were assessed in healthy volunteers using electroencephalography (EEG), single- photon emission computed tomography (SPECT), and structural and functional magnetic resonance imaging (MRI and fMRI, respectively). ${ }^{21,25,26}$ Results from EEG studies are inconsistent and sometimes conflicting (Table 2) ${ }^{26}$. For instance, although reduced power in the alpha, delta and theta bands was observed in some studies $^{14,27-29}$, it was not reported in others ${ }^{19,24}$. Likewise, increased power in the beta band was reported in some studies $19,24,27$ but not in others $14,28,29$. Increased gamma power was not reported in most studies ${ }^{26,29}$. Regarding other serotonergic hallucinogens, reductions in alpha power were also observed in studies with psilocybin and LSD, an effect that seem to underlie the visual effects of these compounds through their agonism at cortical $5-\mathrm{HT}_{2 \mathrm{~A}}$ receptors ${ }^{14,26,30,31}$.

In the last 10 years, the neural basis of the effects of ayahuasca have been investigated using SPECT, MRI and fMRI (Table 2)21,25,26. A SPECT study of acute administration with healthy volunteers showed that ayahuasca increased bilateral activation of the anterior insula/inferior frontal gyrus, right hemisphere activation of the anterior cingulate cortex (ACC) and frontomedial cortex, and left hemisphere activation of the amygdala and parahippocampal gyrus ${ }^{32}$. These brain areas are involved in the modulation of emotions, internal feelings and sensations, perception and self-awareness. An fMRI study using an imagery task showed that ayahuasca not only increased activation of the parahippocampal and frontopolar cortices, but also of the cuneus and lingual gyrus and retrosplenial cortex ${ }^{20}$. Interestingly, during the imagery task ayahuasca increased activation of the primary visual area in a manner similar to the activation levels of seeing a natural image with the eyes open. This effect may be one explanation to the so vivid and "real" effects of the ayahuasca experience. Moreover, a significant correlation was observed between cortical area BA17 activation and BPRS (Brief Psychiatric Ratings Scale) data. Finally, ayahuasca reversed fronto-occipital connectivity, what seems to mean that the visions induced by ayahuasca may be initiated in the primary visual cortex. The difference between this study and the SPECT study, where visual areas were not activated, may be determined by the task since in the fMRI study subjects were instructed to do tasks related with visual stimulation and/or imagery.

Table 2. Effects of ayahuasca on the human brain

\begin{tabular}{|l|}
\hline EEG (acute) ${ }^{14,19,24,26-29}$ \\
\hline Reduced power in the alpha, delta and theta bands \\
\hline Increased power in the beta and gamma bands \\
\hline Neuroimaging (acute) ${ }^{20,32,33}$ \\
\hline $\begin{array}{l}\text { Increased activation of frontal and limbic areas (parahippocampal gyrus, insula, } \\
\text { amygdala, visual and frontal cortices, ACC) (SPECT, fMRI) }\end{array}$ \\
\hline Increased activation of the primary visual area during an imagery task (fMRI) \\
\hline Decreased activation of key hubs of the DMN (PCC, mPFC, precuneus) (fMRI) \\
\hline Decreased functional connectivity within the PCC/precuneus (fMRI) \\
\hline Neuroimaging (long-term)34 \\
\hline Cortical thickening in precentral gyrus and ACC (CT) \\
\hline $\begin{array}{l}\text { Cortical thinning in the mesotemporal and inferior frontal gyri, precuneus, } \\
\text { superior frontal gyrus, PCC, and superior occipital gyrus (CT) }\end{array}$ \\
\hline
\end{tabular}

ACC: anterior cingulate cortex; CT: cortical thickness; DMN: default mode network EEG: electroencephalography; $f M R I$ : functional magnetic resonance imaging; mPFC: medial prefrontal cortex; PCC: posterior cingulate cortex; SPECT: single-photon emission computed tomography.

A resting-state fMRI study showed that ayahuasca decreased activation of key hubs of the default mode network (DMN), including the posterior cingulate (PCC) and the medial prefrontal cortices and the precuneus ${ }^{33}$. Furthermore, ayahuasca decreased functional connectivity within the PCC/precuneus. Studies with psilocybin and LSD also show that these drugs produce their effects by modulating brain structures involved in emotional processing and in memory and self-awareness, such as the parahippocampal gyrus, visual and frontal cortices, ACC and PCC, insula and amygdala15,21,25,26,30,31.

An MRI study assessing cortical thickness in long-term ritual ayahuasca users showed that regular use (average 5.3 years, range 
2-13 years) was associated with cortical thinning in the mesotemporal and inferior frontal gyri, precuneus, superior frontal gyrus, PCC and superior occipital gyrus. On the other hand, increased cortical thickening was observed in precentral gyrus and ACC 34 . Importantly, these structural characteristics were not associated with increased psychopathology among ayahuasca users. Moreover, cortical thinning in the PCC was inversely correlated to age of onset and intensity of prior ayahuasca use and to core on a "self-transcendence" scale. Ayahuasca users also scored better in some neuropsychological tasks related with executive functions compared to controls that were were matched in fluid and verbal IQ, age and gender, among others variables.

\section{Therapeutic potentials}

Ayahuasca has been traditionally used by indigenous groups and mestizo populations for getting in contact with the sacred or supernatural world, for political and artistic purposes, and also for healing ${ }^{1,2,35}$. Nevertheless, the worldview and culture of these populations, and the way they understand and use ayahuasca, are often different from those of nonindigenous populations. Thus, it is not always possible to translate a therapeutic effect described in a traditional context to the concepts of diseases that are shared in the nonindigenous culture. However, over the last 30 years, an increasing number of anecdotal reports and experimental evidence has accumulated suggesting that ayahuasca may have therapeutic potentials in the treatment of difficult-to-treat psychiatric disorders such as drug dependence and anxiety and mood disorders $21,25,36$.

Preclinical studies and observational studies of ayahuasca users suggest that ayahuasca has anxiolytic, antidepressive and antiaddictive effects (Table 3) $21,34,37-40$. Regarding anxiolytic and antidepressive effects in humans, a double-blind, placebo-controlled studies with nine experienced ayahuasca users showed that a single ayahuasca dose was associated with less panic symptoms and reduced hopelessness ${ }^{41}$. An open-label study by our group showed that a single ayahuasca dose was associated with rapid and sustained reductions in anxiety and depressive symptoms in 17 patients with treatment-resistant major depressive disorder ${ }^{42}$. The anxiolytic and antidepressive effects were observed already in the first hours after ayahuasca intake and remained significant for 21 days. Moreover, SPECT imaging showed that ayahuasca administration was associated with increased blood perfusion in the left nucleus accumbens, right insula, and left subgenual area, brain regions associated with emotional processing and the therapeutic effects of traditional antidepressants. These results were partially replicated by our group in a recent parallel arm, double-blind, randomized, placebo-controlled trial in which 35 patients with treatment-resistant major depression received a single dose of ayahuasca or placebo ${ }^{43}$. Compared with patients that received placebo, patients that received ayahuasca had lower depressive symptoms seven days after drug administration. These results are in agreement with recent studies showing anxiolytic and antidepressive effects of serotonergic hallucinogens such as psilocybin and LSD ${ }^{36,44-47}$. Regarding antiaddictive effects in humans, although there are no controlled trials, non-controlled studies in therapeutic and ritual settings suggest that ayahuasca use may have antiaddictive effects ${ }^{48,49}$. Moreover, studies with psilocybin and LSD also suggest that hallucinogenic compounds that act as $5-\mathrm{HT}_{2 \mathrm{~A}}$ agonists have antiaddictive effects ${ }^{36,50,51}$.

Table 3. Main therapeutic potentials of ayahuasca

\begin{tabular}{|l|}
\hline Evidence from uncontrolled studies \\
\hline $42,48,49$ \\
\hline Anxiolytic \\
\hline Antidepressive \\
\hline Antiaddictive \\
\hline Evidence from controlled studies 41,43 \\
\hline Anxiolytic \\
\hline Antidepressive \\
\hline
\end{tabular}

\section{Safety and toxicity}

Classic or serotonergic hallucinogens including LSD, psilocybin, mescaline and DMT are considered drugs with low physiological toxicity that can be safely administered in controlled settings, including both ritual and experimental/clinical contexts $8,17,25,26,36,52,53$. Recent human studies involving acute administration of LSD and psilocybin to healthy volunteers and to patients with drug dependence or anxiety and mood disorders show that these drugs induce significant subjective and physiological effects that are transient, well tolerated, and apparently associated with therapeutic effects $13,15,30,31,44,47,50,51,53$.

In the specific case of ayahuasca, in the last 30 years a few observational studies of long-term ayahuasca users were conducted, and their results suggest that ritual use of this substance is not associated with increased psychopathology or cognitive deficits ${ }^{21,34,37,38,54-57}$. Moreover, a clinical evaluation of long-term (at least 10 years) ritual ayahuasca users, including blood analysis and assessments of cardiovascular, endocrine, immunological, hepatic and renal function, did not show any clinically relevant findings compared to a control groups without ayahuasca use ${ }^{58}$. However, in these studies the samples are mostly composed of experienced users well adapted to the effects of ayahuasca and that are long-term members of organized religious groups. Thus, these participants may have specific characteristics that could limit the generalization of the results. Moreover, although psychiatric complications such as anxiety and psychotic reactions associated with ritual ayahuasca are rare, they may occur, especially among vulnerable individuals ${ }^{21-23}$. In the ritual contexts of ayahuasca use, individuals with a personal or family history of psychotic illness or that are currently with psychotic symptoms are generally not allowed to use ayahuasca or are advised that they should avoid it ${ }^{23,59}$. This could explain at least in part the low incidence of psychotic reactions among ritual ayahuasca users, and show that individuals with a personal or family history of psychotic illness or nonpsychotic mania should avoid ayahuasca use 23,59 .

Regarding experimental and clinical studies of acute ayahuasca administration, several studies performed in the last 15 years with both healthy volunteers and clinical populations consistently show that ayahuasca can be safely administered in the laboratory $y^{5,14,18-21,24,27-29,32,33,36,41-43}$. The most common adverse reactions to ayahuasca are nausea and vomiting, which is often accompanied by other somatic-dysphoric effects such as feeling heat and/or cold and gastrointestinal discomfort (Table 4) $18,19,24,42,43$. In ritual contexts, vomiting is not interpreted as negative, being understood as a cleansing process ${ }^{2}, 16,35$. In early laboratory studies using freezedried ayahuasca, vomiting was observed in four of 53 ayahuasca administrations $(7.5 \%)^{5,18,60}$. In a subsequent study by the same group involving the administration of two consecutive ayahuasca doses four hours apart, only nine of the 17 enrolled volunteers completed the trial, and five of them were excluded from the trial due to vomiting (self-induced in one case), since it was a pharmacokinetic study ${ }^{19}$. In our open-label study involving the administration of a single ayahuasca dose to 17 patients with treatment-resistant major depressive disorder, vomiting was the only adverse effect reported and occurred in $47 \%$ of the volunteers ${ }^{42}$. In our subsequent randomized controlled trial, the most common adverse reaction were nausea (71\%), vomiting (57\%), transient anxiety (50\%), transient headache (42\%), and restlessness $(50 \%)^{43}$.

As discussed above in the topic on the physiological effects of ayahuasca, acute administration of this substance may induce transient and moderate increases in blood pressure and heart rate, in both healthy volunteers and depressed patients ${ }^{5,18,19,42,60}$. However, since the cardiovascular effects of ayahuasca were only assessed in studies of acute administration to young volunteers without cardiovascular complications, the long-term effects of continuous ayahuasca intake and its use by older individuals or by people with hypertension or other cardiac disorders are not known. Although the above-mentioned study among experienced ayahuasca user did not find evidence of increased incidence of cardiovascular diseases in 
this group compared to the control group, seven electrocardiographic alterations were found in the ayahuasca group (one case of right branch bundle block, one of left branch bundle block, one of diffuse ventricular repolarization disturbance, and four of sinusal bradycardia), while among the controls there was only a single case of sinusal bradycardia ${ }^{58}$. Moreover, although these alterations were not clinically relevant, this is only a single study, and a recent study by our group showed that ayahuasca altered some structural parameters of the rat aorta ${ }^{6}$. Thus, more studies are needed to better clarify the cardiovascular effects of ayahuasca, especially the long-term effects.

Although ayahuasca administration in the experimental or clinical setting may induce anxiety and psychotic/psychotomimetic or dissociative symptoms, these effects are usually mild and short-lived, and most participants consider the experience pleasant $18,20,21,42,43,60$. Its important to highlight that individuals with a personal or family history of psychotic illness or nonpsychotic mania are usually not enrolled in these studies, which could explain the absence of reports of prolonged dysphoric or psychotic reaction in the experimental and clinical settings $5,14,18-21,23,24,27-29,32,33,36,41-43,60$. These results are in line with experimental and clinical studies with other serotonergic hallucinogens such as LSD and psilocybin ${ }^{13,15,30,31,36,44-47,50-53}$.

\section{Limitations of the studies}

Although the number of observational studies of long-term ayahuasca users and of studies involving ayahuasca administration to both healthy volunteers and clinical populations has increased over the last years, most of them share similar limitations that render their results preliminary and inconsistent. For instance, most studies of acute and subacute effects, both uncontrolled and controlled, had small sample sizes. Long-term studies usually had bigger samples, but some studies also had small samples. Moreover, several studies were open-label, observational, or had no control groups. Thus, it is difficult to affirm that ayahuasca had a causal role in the observed effects. In several studies where multiple comparisons were performed, there was no statistical correction for this, which could inflate false positive results by reporting variables that show positive results even when a large number of variables exist for small sample sizes. Another important limitation is that some of the subjective effects of ayahuasca were measured with questionnaires that did not have their psychometric qualities validated, which basically means that maybe they were not measuring what they say they were ${ }^{62}$.

Despite these important limitations, many of the results seem to be consistent among different studies ${ }^{21,25,26,36}$, and recent studies with other hallucinogenic compounds that also act as serotonin $5-\mathrm{HT}_{2 \mathrm{~A}}$ receptor agonists, such as psilocybin and LSD, further support these findings $8,25,26,36,53$. Nevertheless, it is important to highlight the fact that some of these studies share the same limitations as those observed in ayahuasca studies, especially regarding small sample sizes and lack of a double-blind design ${ }^{31,45,50,51}$. Therefore, future studies should be well designed. What we are observing in psychedelic research in general and in ayahuasca research in particular is that in the one hand, there are several studies that have published only preliminary results but that do not mention their most important limitations and that are even popularizing these results in the media, leading both the general public and the scientific community to conclusions that cannot be achieved from the original research. On the other hand, almost none of the findings obtained were replicated until the present moment. Thus, in many review papers assertions appear citing papers with preliminary research as if those assertions were already confirmed. Studies methodically well designed, data analysis performed with proper statistical analysis, and the limitations completely described are urgent needs to improve this research field, so that we can avoid falling into the criticism and lack of trust from the scientific community regarding the psychedelic research performed in the 1950-1970' $\mathrm{s}^{63}$.

\section{Suggestions for future research}

Besides the methodological issues commented above, there are other areas of ayahuasca research that could be explored. For instance, the antidepressive and anxiolytic effects of ayahuasca in patients with treatment-resistant major depressive disorder should be further explored in other clinical populations in randomized controlled trials with bigger samples and using different dosage schemes (multiple or repeated doses) to assess safety, tolerability, efficacy, and to compare to the results of single doses. Moreover, the antidepressive and anxiolytic effects of ayahuasca should be evaluated in other anxiety and mood disorders. For instance, recent studies with LSD and psilocybin for depression and anxiety in patients with life-threatening cancer reported promising results, and ayahuasca could also be evaluated in this clinical population $44,46,47$. Regarding drug dependence, although there is evidence from animal studies and from anecdotal reports and uncontrolled studies suggesting that ayahuasca has antiaddictive properties $21,38,40,48,49,54,57$, no controlled trials were ever performed and they are urgent needed.

Another area that should be better investigated is related to the possible chemical interactions between ayahuasca and other compounds such as certain foods, recreational drugs, psychoactive plants, or medications in general. Some studies suggest that there is a risk of serotonin syndrome with the concomitant ingestion of ayahuasca and antidepressants or other pro-serotonergic drugs, but more studies are needed in this area ${ }^{64,65}$. Other area of research focus should be the health contraindications to ayahuasca use. For instance, there is no information regarding the possible effects of ayahuasca in people with cardiovascular disease, and more research is needed on the cardiovascular effects of chronic ayahuasca intake.

There is also a lack of information regarding the possible effects of ayahuasca (harmful or beneficial) on people suffering neuropsychiatric diseases such as epilepsy, Parkinson's disease and Alzheimer's disease, or in those with autoimmune and neuroinflammatory diseases ${ }^{11,12}$. In the specific case of Parkinson's disease, early evidence shows that harmine was used to treat symptoms of this disease in the late 1920 s and early $1930 \mathrm{~s}^{66}$. Evidence supporting this use has been recently reported in preclinical studies using B. caapi extract ${ }^{67}$ and also in a double-blind, randomized, placebo-controlled trial in which B. caapi extracts improved motor function in these patients ${ }^{68}$. The benefits obtained by the use of $B$. caapi were more significant than the results showed by harmine alone, which may suggest and "entourage" effect that should also be considered in ayahuasca research. Probably, the different alkaloids present in the vine "cooperate" to produce a final effect more effective than the different compounds in their pure form and separately. Therefore, more research in this area is needed.

Recent reports suggest the possible role of harmine in neurogenesis ${ }^{69}$. Furthermore, it is known that DMT act as an agonist at $5-\mathrm{HT}_{1 \mathrm{~A}}$ receptors 8,70 . The activation of $5-\mathrm{H}_{1 \mathrm{~A}}$ receptors may be in the basis of neurogenesis in the hippocampus and in the prefrontal cortex and its activation seems to be in the basis of the antidepressant effects of antidepressive drugs ${ }^{71}$.

Regarding adverse effects, a recent study from the United States showed that 538 calls related to ayahuasca use were reported between

Table 4. Main adverse reactions associated with ayahuasca intake

\begin{tabular}{|l|}
\hline Physical symptoms (acute) $16,18-21$ \\
\hline Moderate increases in blood pressure and heart rate \\
\hline Gastrointestinal discomfort \\
\hline Nausea \\
\hline Vomiting \\
\hline Diarrhea (less common) \\
\hline Restlessness \\
\hline Headache \\
\hline Psychological symptoms (acute/subacute) $16,18,20-22$ \\
\hline Anxiety, panic, and fear \\
\hline Psychotic symptoms (less common) \\
\hline Psychological symptoms (prolonged)23,59 \\
\hline Psychotic reactions (rare) \\
\hline
\end{tabular}


September 1, 2005 to September 1, 2015 to the American Association of Poison Controls Centers' (AAPCC) National Poison Data System (NPDS) ${ }^{72}$. Most cases involved acute intoxication in young male adults and were considered of major or moderate clinical significance, and included symptoms such as hallucinations, tachycardia, agitation, hypertension, mydriasis and vomiting. Importantly, 28 cases required endotracheal intubation, and there were four cases of cardiac arrest, seven of respiratory arrest, 12 of seizures, and three fatalities. Unfortunately, there is no detailed description of the cases, which makes it difficult to affirm that all of them were directly caused only by ayahuasca. Indeed, some of the mediatic and scientific descriptions of severe intoxications supposedly caused by ayahuasca could possibly be referring to the result of a combination of several factors, including the addition of more toxic plants to the ayahuasca preparation (such as some Brugmansia species) and the previous physical and mental health of the person drinking ayahuasca, including the medications being used by this person ${ }^{73}$. Moreover, it appears that such cases seem to be more common on countries where ayahuasca is not part of the local religious traditions (such as the United States), and seem to be less common in countries where ayahuasca is part of the culture (such as Brazil, Peru and Colombia) ${ }^{72,73}$. Furthermore, several of the incidents reported in South American countries involved North Americans or Europeans ${ }^{72,73}$. Maybe the tourism around ayahuasca is bringing to Amazonian countries foreigners with health problems that are not always screened by all people organizing ayahuasca rituals, and maybe some people organizing these rituals outside South America are serving ayahuasca to people that they do not know their previous health condition.

Regarding the incidence of prolonged dysphoric reactions to ayahuasca use, characterized by anxiety, panic, or psychotic symptoms, the research conducted so far in this area is limited to anecdotal evidence, case reports and case series, and should be further developed $22,23,59$. It seems that only a minority of individuals suffer such reactions, and in many of those cases these individuals had personal or family histories of psychiatric disorders $22,23,59$. This kind of reaction have not been reported in experimental and clinical studies with ayahuasca ${ }^{21,23,36}$ and are also rare in the case of controlled administration of other hallucinogens ${ }^{36,52,53}$. It seems that carefully screening the volunteers to exclude individuals with some predisposition to psychotic disorders is an important measure to reduce the possibility of the occurrence of such cases $23,52,53$. Future research should focus on trying to better identity who are those individuals more prone to suffer a prolonged dysphoric or psychotic reaction to ayahuasca.

In the last 20 years, an increasing number of neuroimaging studies involving the administration of classic hallucinogens to humans has been conducted, and this area is still in full development 25,26 . Compared to other hallucinogens such as psilocybin, neuroimaging studies with ayahuasca are still small in number, but this picture should change in the near future since there is an increasing number of studies with ayahuasca ${ }^{20,25,26,32-34,42}$. Areas that are currently being investigated and that should be further explored include the study of the neural basis of the antidepressant and anxiolytic effects of ayahuasca and its effects on the default mode network (DMN), a network whose alteration may be related to diseases that go from autism to schizophrenia or depression, and on brain areas that regulate emotions, memory, and higher cognition including self-awareness and introspection ${ }^{20,25,26,32-34,42}$. Moreover, recent uncontrolled studies suggest that ayahuasca may increase mindfulness capacities and creativity ${ }^{74-76}$ Thus, studies with improved methodologies that include controlled designs and neuroimaging could improve our understanding of this possible effects of ayahuasca and the possible association between them and the therapeutic properties of ayahuasca.

Finally, another area that should be better investigated is related to the individual effects of DMT and the $\beta$-carbolines. Indeed, recent studies suggest that endogenous DMT, through the sigma-1 receptor, could be involved in physiological processes such as immunity and inflammatory responses, and also tissue protection and regeneration ${ }^{11,12}$. The fact is that we still do not know what DMT is doing in our bodies, so this is a very interesting topic to further investigate ${ }^{9,10}$. Moreover, preclinical studies suggest that DMT and the $\beta$-carbolines have not only antidepressive, anxiolytic, and antiaddictive proprieties 39,40 , but also neuroprotective and neurotrophic potentials ${ }^{69,77-79}$. For instance, a recent neuropsychological study in ayahuasca user suggested that ayahuasca may indeed improve cognition and have "nootropic" effect ${ }^{80}$. However, although the preclinical data on antidepressive, anxiolytic, and antiaddictive potentials of ayahuasca and its alkaloids has been replicated to some extend in preliminary observational and clinical studies in humans, with the exception of the neuropsychological study just commented, studies on possible neuroprotective and neurotrophic effects are still on the basic level. Future studies should further explore this area.

\section{Declaration of conflicting interests and source of funding}

RGS is Fellow of the Brazilian National Post-Doctorate Program (PNPD/Capes) and member of the ICEERS Advisory Board. JCB is the Scientific Investigations Director of ICEERS. ICEERS is a nonprofit organization that promotes the scientific research of ayahuasca. JECH receives a CNPq (Brazil) Productivity Fellowship Award. None of the authors received any specific funding for participating in this investigation. All authors had full access to all the data and had final responsibility for the decision to submit for publication. The authors have no conflict of interests to disclose.

\section{References}

1. Schultes RE, Hofmann A. Plants of the Gods: their sacred, healing, and hallucinogenic powers. Rochester, VT: Healing Arts Press; 1992.

2. Labate BC, Rose IS, dos Santos RG. Ayahuasca religions: a comprehensive bibliography and critical essays. Santa Cruz, CA: Multidisciplinary Association for Psychedelic Studies; 2009.

3. Labate BC, Feeney K. Ayahuasca and the process of regulation in Brazil and internationally: implications and challenges. Int J Drug Policy. 2012;23(2):154-61.

4. McKenna DJ, Towers GH, Abbott F. Monoamine oxidase inhibitors in South American hallucinogenic plants: tryptamine and beta-carboline constituents of ayahuasca. J Ethnopharmacol. 1984;10(2):195-223.

5. Riba J, Valle M, Urbano G, Yritia M, Morte A, Barbanoj MJ. Human pharmacology of ayahuasca: subjective and cardiovascular effects, monoamine metabolite excretion, and pharmacokinetics. J Pharmacol Exp Ther. 2003;306(1):73-83.

6. Riba J, McIlhenny EH, Bouso JC, Barker SA. Metabolism and urinary disposition of N,N-dimethyltryptamine after oral and smoked administration: a comparative study. Drug Test Anal. 2015;7(5):401-6.

7. Moreno JL, Holloway T, Albizu L, Sealfon SC, González-Maeso J. Metabotropic glutamate $\mathrm{mGlu2}$ receptor is necessary for the pharmacological and behavioral effects induced by hallucinogenic $5-\mathrm{HT}_{2 \mathrm{~A}}$ receptor agonists. Neurosci Lett. 2011;493(3):76-9.

8. Nichols DE. Psychedelics. Pharmacol Rev. 2016;68(2):264-355.

9. Barker SA, Monti JA, Christian ST. N,N-dimethyltryptamine: an endogenous hallucinogen. Int Rev Neurobiol. 1981;22:83-110.

10. Barker SA, McIlhenny EH, Strassman R. A critical review of reports of endogenous psychedelic N,N-dimethyltryptamines in humans: 1955 2010. Drug Test Anal. 2012;4(7-8):617-35.

11. Frecska E, Szabo A, Winkelman MJ, Luna LE, McKenna DJ. A possibly sigma-1 receptor mediated role of dimethyltryptamine in tissue protection, regeneration, and immunity. J Neural Transm. 2013;120(9):1295303.

12. Szabo A, Kovacs A, Frecska E, Rajnavolgyi E. Psychedelic N,N-dimethyltryptamine and 5-methoxy-N,N-dimethyltryptamine modulate innate and adaptive inflammatory responses through the sigma-1 receptor of human monocyte-derived dendritic cells. PLoS One. 2014;9(8):e106533.

13. Vollenweider FX, Vollenweider-Scherpenhuyzen MF, Bäbler A, Vogel H, Hell D. Psilocybin induces schizophrenia-like psychosis in humans via a serotonin-2 agonist action. Neuroreport. 1998;9(17):3897-902. 
14. Valle M, Maqueda AE, Rabella M, Rodríguez-Pujadas A, Antonijoan RM, Romero S, et al. Inhibition of alpha oscillations through serotonin-2A receptor activation underlies the visual effects of ayahuasca in humans. Eur Neuropsychopharmacol. 2016;26(7):1161-75.

15. Preller KH, Herdener M, Pokorny T, Planzer A, Kraehenmann R, Stämpfli P, et al. The Fabric of Meaning and Subjective Effects in LSD-Induced States Depend on Serotonin 2 A Receptor Activation. Curr Biol. 2017;27(3):451-7.

16. Shanon B. The Antipodes of the Mind: Charting the Phenomenology of the Ayahuasca Experience. New York, NY: Oxford University Press; 2002.

17. Preller KH, Vollenweider FX. Phenomenology, structure, and dynamic of psychedelic states. Curr Top Behav Neurosci. 2017. doi: 10.1007/7854_2016_459.

18. Riba J, Rodríguez-Fornells A, Urbano G, Morte A, Antonijoan R, Montero $\mathrm{M}$, et al. Subjective effects and tolerability of the South American psychoactive beverage Ayahuasca in healthy volunteers. Psychopharmacology. 2001;154(1):85-95.

19. Dos Santos RG, Grasa E, Valle M, Ballester MR, Bouso JC, Nomdedéu JF, et al. Pharmacology of ayahuasca administered in two repeated doses. Psychopharmacology. 2012;219(4):1039-53.

20. De Araujo DB, Ribeiro S, Cecchi GA, Carvalho FM, Sanchez TA, Pinto JP, et al. Seeing with the eyes shut: neural basis of enhanced imagery following ayahuasca ingestion. Hum Brain Mapp. 2012;33(11):2550-60.

21. Dos Santos RG, Balthazar FM, Bouso JC, Hallak JE. The current state of research on ayahuasca: A systematic review of human studies assessing psychiatric symptoms, neuropsychological functioning, and neuroimaging. J Psychopharmacol. 2016;30(12):1230-47.

22. Dos Santos RG, Osório FL, Crippa JA, Hallak JE. Anxiety, panic and hopelessness during and after ritual ayahuasca intake in a woman with generalized anxiety disorder: a case report. J Psychedelic Studies. 2017. doi: 10.1556/2054.01.2016.001.

23. Dos Santos RG, Bouso JC, Hallak JE. Ayahuasca, dimethyltryptamine, and psychosis: a systematic review of human studies. Ther Adv Psychopharmacol. 2017. doi: 10.1177/2045125316689030.

24. Dos Santos RG, Valle M, Bouso JC, Nomdedéu JF, Rodríguez-Espinosa J, Mcllhenny EH, et al. Autonomic, neuroendocrine, and immunological effects of ayahuasca: a comparative study with $d$-amphetamine. J Clin Psychopharmacol. 2011;31(6):717-26.

25. Dos Santos RG, Osório FL, Crippa JA, Hallak JE. Classical hallucinogens and neuroimaging: A systematic review of human studies. Neurosci Biobehav Rev. 2016;71:715-28.

26. Tófoli LF, de Araujo DB. Treating addiction: Perspectives from EEG and imaging studies on psychedelics. Int Rev Neurobiol. 2016;129:157-85.

27. Riba J, Anderer P, Morte A, Urbano G, Jané F, Saletu B, et al. Topographic pharmaco-EEG mapping of the effects of the South American psychoactive beverage ayahuasca in healthy volunteers. Br J Clin Pharmacol. 2002;53(6):613-28.

28. Riba J, Anderer P, Jané F, Saletu B, Barbanoj MJ. Effects of the South American psychoactive beverage ayahuasca on regional brain electrical activity in humans: a functional neuroimaging study using low-resolution electromagnetic tomography. Neuropsychobiology. 2004;50(1):89-101.

29. Schenberg EE, Alexandre JF, Filev R, Cravo AM, Sato JR, Muthukumaraswamy SD, et al. Acute biphasic effects of ayahuasca. PLoS One. 2015;10(9):e0137202.

30. Kometer M, Schmidt A, Jäncke L, Vollenweider FX. Activation of serotonin $2 \mathrm{~A}$ receptors underlies the psilocybin-induced effects on a oscillations, N170 visual-evoked potentials, and visual hallucinations. J Neurosci. 2013;33(25):10544-51.

31. Carhart-Harris RL, Muthukumaraswamy S, Roseman L, Kaelen M, Droog W, Murphy K, et al. Neural correlates of the LSD experience revealed by multimodal neuroimaging. Proc Natl Acad Sci U S A. 2016;113(17): 4853-8.

32. Riba J, Romero S, Grasa E, Mena E, Carrió I, Barbanoj MJ. Increased frontal and paralimbic activation following ayahuasca, the pan-Amazonian inebriant. Psychopharmacology. 2006;186(1):93-8.

33. Palhano-Fontes F, Andrade KC, Tofoli LF, Santos AC, Crippa JA, Hallak JE, et al. The psychedelic state induced by ayahuasca modulates the activity and connectivity of the default mode network. PLoS One. 2015;10(2):e0118143.
34. Bouso JC, Palhano-Fontes F, Rodríguez-Fornells A, Ribeiro S, Sanches $\mathrm{R}$, Crippa JA, et al. Long-term use of psychedelic drugs is associated with differences in brain structure and personality in humans. Eur Neuropsychopharmacol. 2015;25(4):483-92.

35. Luna LE. Indigenous and mestizo use of ayahuasca. An overview. In: dos Santos RG, editor. The Ethnopharmacology of Ayahuasca. Trivandrum, India: Transworld Research Network; 2011. p. 1-21. Available at: <https:// www.researchgate.net/publication/307462153_1_Indigenous_and_mestizo_use_of_ayahuasca_An_overview $>$.

36. Dos Santos RG, Osório FL, Crippa JA, Riba J, Zuardi AW, Hallak JE. Antidepressive, anxiolytic, and antiaddictive effects of ayahuasca, psilocybin and lysergic acid diethylamide (LSD): a systematic review of clinical trials published in the last 25 years. Ther Adv Psychopharmacol. 2016;6(3):193-213.

37. Bouso JC, González D, Fondevila S, Cutchet M, Fernández X, Ribeiro Barbosa PC, et al. Personality, psychopathology, life attitudes and neuropsychological performance among ritual users of ayahuasca: a longitudinal study. PLoS One. 2012;7(8):e42421.

38. Barbosa PC, Strassman RJ, da Silveira DX, Areco K, Hoy R, Pommy J, et al. Psychological and neuropsychological assessment of regular hoasca users. Compr Psychiatry. 2016;71:95-105.

39. Dos Santos RG, Osório FL, Crippa JA, Hallak JE. Antidepressive and anxiolytic effects of ayahuasca: a systematic literature review of animal and human studies. Rev Bras Psiquiatr. 2016;38(1):65-72.

40. Nunes AA, Dos Santos RG, Osório FL, Sanches RF, Crippa JA, Hallak JE. Effects of ayahuasca and its alkaloids on drug dependence: A systematic literature review of quantitative studies in animals and humans. J Psychoactive Drugs. 2016;48(3):195-205.

41. Dos Santos RG, Landeira-Fernandez J, Strassman RJ, Motta V, Cruz AP. Effects of ayahuasca on psychometric measures of anxiety, panic-like and hopelessness in Santo Daime members. J Ethnopharmacol. 2007;112(3):507-13.

42. Sanches RF, de Lima Osório F, Dos Santos RG, Macedo LR, Maia-de-Oliveira JP, Wichert-Ana L, et al. Antidepressant effects of a single dose of ayahuasca in patients with recurrent depression: A SPECT study. J Clin Psychopharmacol. 2016;36(1):77-81.

43. Palhano-Fontes F, Barreto D, Onias H, Andrade KC, Novaes M, Pessoa $\mathrm{J}$, et al. Rapid antidepressant effects of the psychedelic ayahuasca in treatment-resistant depression: a randomised placebo-controlled trial. bioRxiv 103531; doi: https://doi.org/10.1101/103531.

44. Gasser P, Holstein D, Michel Y, Doblin R, Yazar-Klosinski B, Passie T, et al Safety and efficacy of lysergic acid diethylamide-assisted psychotherapy for anxiety associated with life-threatening diseases. J Nerv Ment Dis. 2014;202(7):513-20.

45. Carhart-Harris RL, Bolstridge M, Rucker J, Day CM, Erritzoe D, Kaelen M, et al. Psilocybin with psychological support for treatment-resistant depression: an open-label feasibility study. Lancet Psychiatry. 2016;3(7):619-27.

46. Griffiths RR, Johnson MW, Carducci MA, Umbricht A, Richards WA, Richards BD, et al. Psilocybin produces substantial and sustained decreases in depression and anxiety in patients with life-threatening cancer: A randomized double-blind trial. J Psychopharmacol. 2016;30(12):1181-97.

47. Ross S, Bossis A, Guss J, Agin-Liebes G, Malone T, Cohen B, et al. Rapid and sustained symptom reduction following psilocybin treatment for anxiety and depression in patients with life-threatening cancer: a randomized controlled trial. J Psychopharmacol. 2016;30(12):1165-80.

48. Thomas G, Lucas P, Capler NR, Tupper KW, Martin G. Ayahuasca-assisted therapy for addiction: results from a preliminary observational study in Canada. Curr Drug Abuse Rev. 2013;6(1):30-42.

49. Fernández X, Dos Santos RG, Cutchet M, Fondevila S, González D, Alcázar MA, et al. Assessment of the psychotherapeutic effects of ritual ayahuasca use on drug dependency: A pilot study. In: Labate BC, Cavnar C, editors. The therapeutic use of ayahuasca. Berlin/Heidelberg: Springer; 2014. p. 183-96.

50. Johnson MW, Garcia-Romeu A, Cosimano MP, Griffiths RR. Pilot study of the $5-\mathrm{HT}_{2 \mathrm{~A}} \mathrm{R}$ agonist psilocybin in the treatment of tobacco addiction. J Psychopharmacol. 2014;28(11):983-92.

51. Bogenschutz MP, Forcehimes AA, Pommy JA, Wilcox CE, Barbosa PC, Strassman RJ. Psilocybin-assisted treatment for alcohol dependence: A proof-of-concept study. J Psychopharmacol. 2015;29(3):289-99. 
52. Strassman RJ. Adverse reactions to psychedelic drugs. A review of the literature. J Nerv Ment Dis. 1984;172(10):577-95.

53. Studerus E, Kometer M, Hasler F, Vollenweider FX. Acute, subacute and long-term subjective effects of psilocybin in healthy humans: A pooled analysis of experimental studies. J Psychopharmacol. 2011;25(11):1434-52.

54. Grob CS, McKenna DJ, Callaway JC, Brito GS, Neves ES, Oberlaender G, et al. Human psychopharmacology of hoasca, a plant hallucinogen used in ritual context in Brazil. J Nerv Ment Dis. 1996;184(2):86-94.

55. Da Silveira DX, Grob CS, de Rios MD, Lopez E, Alonso LK, Tacla C, et al. Ayahuasca in adolescence: a preliminary psychiatric assessment. J Psychoactive Drugs. 2005;37(2):129-33.

56. Doering-Silveira E, Lopez E, Grob CS, de Rios MD, Alonso LK, Tacla C, et al. Ayahuasca in adolescence: a neuropsychological assessment. J Psychoactive Drugs. 2005;37(2):123-8.

57. Barbosa PC, Mizumoto S, Bogenschutz MP, Strassman RJ. Health status of ayahuasca users. Drug Test Anal. 2012;4(7-8):601-9.

58. Andrade EN, Brito GS, Andrade EO, Neves ES, McKenna DJ, Cavalcante JW, et al. Farmacologia humana da hoasca: estudos clínicos (avaliação clínica comparativa entre usuários do chá hoasca por longo prazo e controles; avaliação fisiológica dos efeitos agudos pós-ingestão do chá hoasca). In: Labate BC, Araújo WS, editors. O uso ritual da ayahuasca. 2nd ed. Campinas: Mercado de Letras; 2004. p. 671-80.

59. Lima F, Tófoli L. An epidemiological surveillance system by the UDV: mental health recommendations concerning the religious use of hoasca. In: Labate BC, Jungaberle $\mathrm{H}$, editors. The internationalization of ayahuasca. Zurich/Berlin: Lit Verlag; 2011. p. 185-99.

60. Riba J, Barbanoj MJ. Bringing ayahuasca to the clinical research laboratory. J Psychoactive Drugs. 2005;37(2):219-30.

61. Pitol DL, Siéssere S, Dos Santos RG, Rosa ML, Hallak JE, Scalize PH, et al. Ayahuasca alters structural parameters of the rat aorta. J Cardiovasc Pharmacol. 2015;66(1):58-62.

62. Bouso JC, Pedrero-Pérez EJ, Gandy S, Alcázar-Córcoles MA. Measuring the subjective: revisiting the psychometric properties of three rating scales that assess the acute effects of hallucinogens. Hum Psychopharmacol. 2016;31(5):356-72.

63. Dakwar E. The death and rebirth of hallucinogens. Drug Alcohol Depend. 2016;165:293-7.

64. Callaway JC, Grob CS. Ayahuasca preparations and serotonin reuptake inhibitors: a potential combination for severe adverse interactions. J Psychoactive Drugs. 1998;30(4):367-9.

65. dos Santos RG. Safety and side effects of ayahuasca in humans: An overview focusing on developmental toxicology. J Psychoactive Drugs. 2013;45(1):68-78.

66. Sanchez-Ramos JR. Banisterine and Parkinson's disease. Clin Neuropharmacol. 1991;14(5):391-402.
67. Schwarz MJ, Houghton PJ, Rose S, Jenner P, Lees AD. Activities of extract and constituents of Banisteriopsis caapi relevant to parkinsonism. Pharmacol Biochem Behav. 2003;75(3):627-33.

68. Serrano-Dueñas M, Cardozo-Pelaez F, Sánches-Ramos JR. Effects of Banisteriopsis caapi extract on Parkinson's disease. Sci Rev Alternative Med. 2001;5(3):127-32.

69. Dakic V, Maciel RM, Drummond H, Nascimento JM, Trindade P, Rehen SK. Harmine stimulates proliferation of human neural progenitors. Peer J. 2016;4:e2727.

70. Strassman RJ. Human psychopharmacology of N,N-dimethyltryptamine. Behav Brain Res. 1996;73(1-2):121-4.

71. Lacivita E, Di Pilato P, De Giorgio P, Colabufo NA, Berardi F, Perrone $\mathrm{R}$, et al. The therapeutic potential of $5-\mathrm{HT}_{1 \mathrm{~A}}$ receptors: a patent review. Expert Opin Ther Pat. 2012;22(8):887-902.

72. Heise CW, Brooks DE. Ayahuasca exposure: descriptive analysis of calls to US Poison Control Centers from 2005 to 2015. J Med Toxicol. 2017. doi: 10.1007/s13181-016-0593-1.

73. dos Santos RG. A critical evaluation of reports associating ayahuasca with life-threatening adverse reactions. J Psychoactive Drugs. 2013;45(2):179-88.

74. Frecska E, Móré CE, Vargha A, Luna LE. Enhancement of creative expression and entoptic phenomena as after-effects of repeated ayahuasca ceremonies. J Psychoactive Drugs. 2012;44(3):191-9.

75. Kuypers KP, Riba J, de la Fuente Revenga M, Barker S, Theunissen EL, Ramaekers JG. Ayahuasca enhances creative divergent thinking while decreasing conventional convergent thinking. Psychopharmacology. 2016;233(18):3395-403.

76. Soler J, Elices M, Franquesa A, Barker S, Friedlander P, Feilding A, et al. Exploring the therapeutic potential of ayahuasca: acute intake increases mindfulness-related capacities. Psychopharmacology. 2016;233(5):823-9.

77. Szabo A, Kovacs A, Riba J, Djurovic S, Rajnavolgyi E, Frecska E. The endogenous hallucinogen and trace amine N,N-dimethyltryptamine (DMT) displays potent protective effects against hypoxia via sigma-1 receptor activation in human primary iPSC-derived cortical neurons and microglia-like immune cells. Front Neurosci. 2016;10:423.

78. Chaurasiya ND, Shukla S, Tekwani BL. A combined in vitro assay for evaluation of neurotrophic activity and cytotoxicity. SLAS Discov. 2017. doi: $10.1177 / 2472555217698677$.

79. Dos Santos RG, Hallak JE. Effects of the natural $\beta$-carboline alkaloid harmine, a main constituent of ayahuasca, in memory and in the hippocampus: A systematic literature review of preclinical studies. J Psychoactive Drugs. 2017;49(1):1-10.

80. Bouso JC, Fábregas JM, Antonijoan RM, Rodríguez-Fornells A, Riba J. Acute effects of ayahuasca on neuropsychological performance: differences in executive function between experienced and occasional users. Psychopharmacology. 2013;230(3):415-24. 